https://doi.org/10.1590/198053146535

\title{
MODOS DE CONSTITUIÇÃO DA DOCENCIA BRASILEIRA: TRADICIONALISMO, COMPETÊNCIA TÉCNICA E BOAS PRÁTICAS
}

Renata Porcher Scherer'

\section{Resumo}

Tendo a docência brasileira como objeto de pesquisa, a partir de uma perspectiva histórica, o presente artigo procura responder ao seguinte questionamento: quais práticas podem ser descritas acerca da docência brasileira na literatura pedagógica da segunda metade do século XX? Realiza-se uma análise documental de três obras de importante impacto na literatura educacional e propõe-se um breve exercício analítico, que, longe de esgotar tais fontes documentais, busca mapear algumas pistas acerca das concepções de pesquisa sobre a docência na educação básica que predominaram no Brasil. Assim, são mapeadas três tendências que compuseram (e ainda compõem) as pautas da pesquisa acadêmica nesse período, quais sejam: na década de 1960, as articulações entre docência e tradicionalismo; na década de 1980, os debates em torno da competência técnica e do compromisso político; e nos anos 1990, a centralidade na prática dos professores.

\section{ENSINO • EDUCAÇÃO BÁSICA • DOCUMENTO HISTÓRICO • BRASIL}

\section{MODES OF CONSTITUTION OF BRAZILIAN TEACHING: TRADITIONALISM, TECHNICAL COMPETENCE AND GOOD PRACTICES}

\begin{abstract}
Having Brazilian teaching as the object of research, this article seeks to answer the following question from a historical perspective: which Brazilian teaching practices are described in the pedagogical literature of the second half of the 20th century? Documentary analysis of three works of great impact in the educational literature is carried out and a brief analytical exercise is proposed. Far from exhausting these documentary sources, this analysis seeks to find some clues about the impact of these concepts on teaching in basic education that predominated in Brazil. Thus, the three trends that comprise (and continue to comprise) the guidelines of academic research in this period are mapped: in the 1960s, the articulations between teaching and traditionalism; in the 1980s, discussions about technical competence and political commitment; and, in the 1990s, centrality in teachers' practice.
\end{abstract}

TEACHING • BASIC EDUCATION・HISTORICAL DOCUMENT • BRAZIL

\footnotetext{
1 O presente trabalho foi realizado com apoio da Coordenação de Aperfeiçoamento de Pessoal de Nivel Superior (Capes) - Código de Financiamento 001.

I Instituto Federal de Educação, Ciência e Tecnologia Sul-rio-grandense (IFSul), Camaquã (RS), Brasil; http://orcid.org/0000-0003-2331-1453; renatapscherer@gmail.com
} 


\section{MODES DE CONSTITUTION DE L'ENSEIGNEMENT BRÉSILIEN: TRADITIONALISME, COMPÉTENCE TECHNIQUE ET BONNES PRATIQUES}

\section{Résumé}

Cet article, dont l'objet de recherche est l'enseignement brésilien, cherche à répondre dans une perspective historique à la question suivante: quelles pratiques d'enseignement sont décrites dans les ouvrages pédagogiques de la seconde moitié du XXe siècle au Brésil? L'étude effectue d'abord une analyse de trois oeuvres d'impact sur le champ educationnel et propose un bref exercice analytique. Loin d'épuiser les sources documentaires, il vise à tracer quelques pistes concernant les conceptions de la recherche en enseignement qui ont prédominé dans l'éducation brésilienne. Trois tendances qui composaient, et composent toujours, les lignes directrices de la recherche de la période sont degagées: les articulations entre enseignement et traditionalisme pour les années 1960; les débats autour de la compétence technique et de l'engagement politique; dans les années 1980 et dans les années 1990, la centralité de la pratique des enseignants.

\section{ENSEIGNEMENT • EDUCATION DE BASE • DOCUMENT HISTORIQUE • BRÉSIL}

\section{MODOS DE CONSTITUCIÓN DE LA DOCENCIA BRASILEÑA: TRADICIONALISMO, COMPETENCIA TÉCNICA Y BUENAS PRÁCTICAS}

\section{Resumen}

Al tener la docencia brasileña como objeto de investigación, desde una perspectiva histórica, el presente artículo intenta contestar la siguiente interrogante: ¿qué prácticas es posible describir acerca de la docencia brasileña en la literatura pedagógica de la segunda mitad del siglo XX? Se realiza un análisis documental de tres obras de importante impacto en la literatura educacional y se propone un breve ejercicio analítico que, en lugar de agotar tales fuentes documentales, trata de mapear algunas pistas acerca de las concepciones de investigación sobre la docencia en la educación básica que predominaron en Brasil. De este modo, se mapean tres tendencias que formaron parte (y todavía forman) de las pautas de la investigación académica en tal periodo, es decir: en la década de 1960, las articulaciones entre docencia y tradicionalismo; en la década de 1980, los debates en torno a la competencia técnica y el compromiso político; y en los años 1990, la centralidad en la práctica de los profesores.

ENSEÑANZA • EDUCACIÓN BÁSICA • DOCUMENTO HISTORICO・BRASIL 
OMPREENDER POR QUE OS RETRATOS DA DOCÊNCIA BRASILEIRA CONTINUAM CONSTITUÍDOS ora em torno da vocação e da maternidade, ora em torno dos saberes técnicos e profissionais é um dos desafios que este artigo assume. Ao escolher a docência brasileira como objeto de pesquisa, a partir de uma perspectiva histórica, o presente estudo propõe-se a responder ao seguinte questionamento: quais práticas podem ser descritas acerca da docência brasileira na literatura pedagógica brasileira da segunda metade do século XX?

Podemos afirmar que, contemporaneamente, a docência tem sido um dos principais focos investigativos das pesquisas acadêmicas em educação (TARDIF, 2010; SANTOMÉ, 2006; GAUTHIER, 2006; HARGREAVES, 1998). Mas nem sempre foi assim; pois, de acordo com a socióloga Silke Weber (1996), poucos estudos eram realizados no Brasil sobre o professor como profissional, destacando-se a década de 1990 como o período em que tal discussão se estabelece no território nacional. A revisão de literatura realizada por Roseli Cação Fontana (2010) corrobora essa afirmação, ao descrever como marco de referência para os estudos sobre a prática e a identidade docente o trabalho pioneiro da pesquisadora Guiomar Namo de Mello, desenvolvido nos anos 1980. Weber (1996) destaca, ainda, que se, por um lado, os estudos relativos ao professor como profissional têm seu início na década de 1990, no Brasil, por outro, estudos sobre a socialização profissional do professor foram inaugurados nos anos 1960, duas décadas antes, sendo realizados principalmente sob o aporte da sociologia.

A respeito dos estudos em docência, a pesquisadora Selma Garrido Pimenta (1996) explica que, nos anos 1990, percebia-se uma forte corrente de desvalorização profissional dos professores e proliferavam concepções que descreviam a docência como uma atividade técnica de reprodução de conhecimentos, ou, 
ainda, como monitoramento de programas previamente elaborados. Para Pimenta (1996), era importante descrever a docência nos termos de responsabilidade pelos processos de mediação da constituição da cidadania dos alunos, buscando combater o fracasso e a desigualdade educacional. É nesse cenário que os estudos que se propuseram a repensar a formação inicial e contínua voltaram-se para as práticas pedagógicas e docentes, tornando-se essa uma das demandas importantes dos trabalhos acadêmicos realizados naquele período. Podemos observar que foi nos anos 1990 que o campo dos estudos em docência passou a se fortalecer e que, nas últimas décadas, tem se tornado necessário redescobrir e reinventar sentidos sobre essa profissão.

Todavia, para que tais estudos possam seguir avançando e para que possamos consolidar uma pauta investigativa sobre a docência brasileira, precisamos investir em estudos históricos que, ao atentarem para a literatura pedagógica, nos auxiliem a seguir nessa direção. Ao analisar a docência como prática, nos aproximamos dos estudos foucaultianos que definem o conceito de prática como uma racionalidade ou regularidade que organiza o que os sujeitos fazem quando falam ou quando agem, podendo constituir experiências ou pensamentos (CASTRO, 2009). As práticas teriam relação tanto com aquilo que pode "ser descrito, analisado e problematizado quanto, ao mesmo tempo, [com] o domínio das próprias descrições, análises e problematizações que são colocadas em movimento" (VEIGA-NETO, 2008, p. 7). Para Foucault, tudo seria prática e tudo estaria imerso em relações de saber que se implicam mutuamente (FISCHER, 2012). “Ou seja, enunciados e visibilidades, textos e instituições, falar e ver constituem práticas sociais por definição permanentemente presas, amarradas às relações de poder, que as supõem e as atualizam" (FISCHER, 2012, p. 75).

Considerando a pulverização discursiva de produções acadêmicas sobre o tema da docência, admitindo ainda uma condição aleatória e não buscando exclusividade, neste artigo é dada atenção especial para a produção acadêmica brasileira da segunda metade do século XX sobre o tema da docência. Analisamos três obras de importante impacto na literatura educacional brasileira e propomos um breve exercício analítico que, longe de esgotar tais fontes documentais, busca mapear algumas pistas acerca das concepções de pesquisa sobre a docência na educação básica que predominaram no Brasil nas décadas de 1960, 1980 e 1990.

O compromisso assumido neste trabalho constitui-se em estabelecer um diagnóstico crítico das três principais tendências analíticas que orientaram a produção acadêmica entre as décadas de 1960 e 1990. Ao realizar um estudo em três tempos, não desejamos nos comprometer com um estudo comparativo ou que esgote cada uma das fontes analisadas. Ao escolher três obras, dentro da intensa produção acadêmica existente no território nacional, buscamos apontar elementos importantes para a construção de um esquema analítico que permita oferecer novos elementos sobre caminhos percorridos pela docência brasileira no período analisado. Para construir esse percurso investigativo, iniciamos pela obra Professôras de amanhã: um estudo de escolha ocupacional, escrita pela socióloga Aparecida Joly Gouveia e publicada em 1965. O destaque com relação a essa obra refere-se às análises da autora acerca das relações entre os graus de tradiciona- 
lismo das moças e sua maior ou menor propensão pela escolha do magistério. O segundo livro analisado - Magistério de $1^{\circ}$ grau: da competência técnica ao compromisso político - foi escrito por Guiomar Namo de Mello e publicado em 1982. Em nossas análises, a atenção volta-se para o debate que fervilhava entre os educadores do período entre a competência técnica e o compromisso político. O terceiro e último livro é a obra 0 bom professor e sua prática, escrito por Maria Isabel da Cunha em 1989. Analisaremos o deslocamento do interesse investigativo na pesquisa acadêmica brasileira para a prática do professor, destacando-se o que acontecia no interior das salas de aula.

\section{DOCÊNCIA E TRADICIONALISMO: PONTO DE PARTIDA}

A obra Professôras de amanhã: um estudo de escolha ocupacional (GOUVEIA, 1970)² apresenta resultados de pesquisas realizadas nos Centros Regionais de Pesquisas Educacionais, que tinham sede em diferentes capitais do país. Tais centros eram ligados ao Instituto Nacional de Estudos e Pesquisas Educacionais Anísio Teixeira (Inep), instituição na qual Gouveia trabalhava como pesquisadora. Os dados obtidos nessa pesquisa consistiram na base para elaboração de sua tese intitulada Professôras de amanhã e defendida na Universidade de Chicago, em 1962, bem como para um artigo intitulado "Milhares de normalistas e milhares de analfabetos”, publicado em 1961 (LÜDKE, 2010).

Paoli (1995), em estudo sobre as contribuições do pensamento sociológico para o campo educacional entre as décadas de 1950 e 1960, divide os estudos de Gouveia a partir de duas matrizes: uma primeira com foco em investigar as opiniões dos pais e professores sobre a escola; e uma segunda voltada para a formação de professores e utilizando de forma mais contundente os recursos das análises estatísticas. Neste artigo analisaremos os estudos da segunda fase de investigação de Gouveia olhando com especial atenção para a obra Professôras de amanhã.

O primeiro trabalho publicado, da segunda fase do pensamento da autora, consiste no artigo "Milhares de normalistas e milhares de analfabetos", no qual Gouveia debate um tema que segue atual para a educação, que é a preparação de professores para o trabalho na educação básica para todos, com destaque para os processos de alfabetização. Segundo Lüdke (2010, p. 43), o título desse artigo anunciava "o nascimento da grande pesquisadora, que já começava a colocar seus talentos, então em pleno desenvolvimento, a serviço do estudo de nossos problemas educacionais, o que faria ao longo de toda sua carreira como uma estrela".

Após mostrar, brevemente, o percurso acadêmico e profissional que permitiu que Gouveia realizasse o estudo que será analisado nesta seção, torna-se importante situar o pano de fundo que inspirou sua investigação. A obra de Gouveia (1970) foi produzida em um período de urbanização do território nacional, no qual apresentava-se como importante investir na educação com foco no progresso e desenvolvimento da nação. Assim, a situação problema que dispara os 
questionamentos da pesquisadora consiste no grande número de analfabetos, em torno de 15 milhões, enquanto o Brasil não chegava a ter 50 milhões de habitantes, diante de um elevado número de professoras formadas pelos cursos normais (cerca de 90.000). Outro aspecto que preocupava Gouveia (1970) referia-se ao dado de que, para cada 1.000 crianças matriculadas na escola primária, apenas 16 chegavam à última série desses cursos.

Para a pesquisadora brasileira, a hipótese explicativa para os problemas dos cursos normais envolveria três noções básicas: manutenção de valores tradicionais da sociedade patriarcal brasileira relativos aos papéis da mulher; o crescimento do nível de aspirações com relação à educação escolar no Brasil daquele período; e o fato de as escolas normais representarem uma solução para, de um lado, manter o papel esperado pela mulher nas sociedades patriarcais e, de outro, ampliar a mão de obra feminina e a oferta de escolarização para a população. Tais questões eram extremamente importantes no contexto de urbanização em que o Brasil encontrava-se, e Gouveia (1970) debruçou-se sobre algumas delas na obra Professôras de amanhã, a qual analisaremos de forma mais detalhada a partir desse momento.

O estudo desenvolvido por Gouveia (1970) tinha como foco as decisões vocacionais das mulheres, em uma sociedade que estava em processo de urbanização. Para tanto, a partir de um olhar sociológico, a autora analisa a influência de dois fatores na escolha das moças pela profissão na década de 1960: a origem social e o grau de tradicionalismo.

Ao longo dessa seção exploramos as relações entre o processo de feminização do magistério no Brasil e a escala de tradicionalismo criada por Gouveia. Pretendemos evidenciar as críticas pioneiras desenvolvidas no estudo de Gouveia (1970) relativas à organização patriarcal da sociedade brasileira, que influenciava tanto a escolha das mulheres pelo magistério como a organização das escolas normais como espaços que buscavam justapor elementos de formação profissional a elementos de preparação para a dedicação exclusiva ao lar. Isto é, para as escolas normais da década de 1960, tão importante quanto formar boas professoras era formar boas esposas. Tal conclusão sinaliza a potencialidade e a originalidade dos estudos de Gouveia e, consequentemente, justifica nossa escolha por tomar essa obra como ponto inicial de nossas reflexões.

Para explorar as relações entre a escala de tradicionalismo e a feminização do magistério, apresentamos, a seguir, as questões que foram utilizadas pela socióloga para desenvolver a escala de tradicionalismo e a principal hipótese que guiou seu estudo.

1. Uma das principais coisas que uma criança deve aprender é a obediência aos pais;

2. A moça não deve casar-se com um rapaz que não é do agrado de seus pais;

3. Mesmo depois de casados, os filhos devem obedecer aos pais;

4. Temos mais obrigação de ajudar a um tio ou primo do que ajudar a um amigo. (GOUVEIA, 1970, p. 37) 
Tal hipótese poderia ser formulada, de maneira mais específica, nos seguintes termos: a posição da mulher em uma escala de tradicionalismo explicaria sua atitude em relação à participação em atividades profissionais, prevendo o esquema que no polo "tradicional" se encontrariam as moças propensas ao padrão da mulher "dona de casa"; distante do polo tradicional, mas não ainda no polo oposto, se encontrariam as propensas ao magistério e, finalmente, neste polo - polo moderno - se encontrariam as moças propensas a "outras" profissões. (GOUVEIA, 1970, p. 36)

No primeiro excerto apresentamos os quatro itens utilizados por Gouveia (1970) em sua escala de tradicionalismo. Após as moças responderem ao questionário, se concordavam ou não com tais afirmações, elas eram distribuídas em três categorias: tradicionais, transicionais e modernas. Essa classificação era importante para Gouveia (1970) confirmar a hipótese orientadora do seu estudo. Para a pesquisadora, importava mostrar uma relação entre dedicação exclusiva ao lar e tradicionalismo; magistério e uma posição intermediária; e escolha por outras profissões e modernismo.

Ao final do capítulo, a autora articula diferentes variáveis, tais como nível socioeconômico, profissão paterna, o fato de a mãe já ter trabalhado fora de casa e a posição das moças na escala de tradicionalismo, para então confirmar uma de suas principais hipóteses, mostrando que existe uma clara relação entre o grau de modernismo das moças e sua menor inclinação para o magistério. Porém, com relação ao grau de tradicionalismo, a pesquisadora aponta que outras variáveis parecem influenciar as inclinações para o magistério: "Desta maneira pode-se verificar que não apenas o grau de tradicionalismo mas também a origem social (ou profissão paterna), a instrução do pai e a instrução da mãe estão relacionadas com o desenvolvimento das inclinações para o magistério" (GOUVEIA, 1970, p. 58).

Segundo a pesquisadora, entre as normalistas que pertenciam à classe social "alta" a hipótese do estudo confirmou-se, estando mais propensas para as atividades do magistério as moças situadas na faixa "transicional" da escala de tradicionalismo. Já entre as normalistas da classe "baixa”, Gouveia verificou que as propensões para cursar o magistério eram maiores para as "tradicionais" do que para as "transicionais". A pesquisadora sugere que esse desvio pode estar relacionado a limitações que as moças da categoria "baixa" ${ }^{2}$ apresentavam em função de "fatores da realidade”. Para Gouveia (1970), a escolha por um padrão de dedicação exclusiva ao lar, que era a principal opção das moças categorizadas como tradicionais na classe "alta”, não se reproduzia nas moças categorizadas na classe "baixa” por não ser viável devido à sua situação econômica.

O que se mostra significativo, para a análise aqui proposta, constitui-se, principalmente, na criação da escala de tradicionalismo e na confirmação da

A escala socioeconômica para classificar as participantes da pesquisa na classe social, alta ou baixa, foi estabelecida com base em um único critério - a profissão paterna. A autora tomou como base os estudos de Bertram Hutchinson (1960) e adaptou-os para a realidade do seu estudo. A autora ainda aponta que "à medida que se desce na escala social, aumenta consistentemente a proporção de moças que aspiram ao magistério. E tais resultados se enquadrariam, perfeitamente, em um esquema de explicação da escolha vocacional formulado em termos de 'fatores da realidade', como os acima sugeridos" (GOUVEIA, 1970, p. 33). 
hipótese estabelecida, em que o grau de tradicionalismo das moças possui uma relação com suas escolhas ocupacionais. A criação da escala de tradicionalismo só foi possível porque, naquela época, já estava consolidada uma visão do magistério em que uma noção associada a uma suposta natureza feminina era relacionada aos papéis desempenhados pela professora. A socióloga destaca como características principais duas questões: é um trabalho desempenhado com crianças; e o fato de a mulher exercer esta ocupação em um espaço onde não estaria exposta "ao contato com estranhos do sexo oposto" (GOUVEIA, 1970, p. 35).

Em análise histórica sobre o processo de formação das escolas normais e os primeiros movimentos relativos à profissionalização do trabalho docente no Brasil, a historiadora Heloisa Villela (2000) mostra que nacionalidade, idade e moral eram critérios utilizados na seleção de quem poderia ingressar nas escolas normais em 1835. Pode-se notar, ainda, pela documentação analisada por Villela, que o peso da exigência de boa conduta moral, para os ingressantes na carreira do magistério, era muito maior do que a necessidade de saber ler e escrever, visto que a comprovação de boa conduta deveria passar, inclusive, pelo juiz de paz e despacho do presidente, enquanto as competências acadêmicas ficavam a cargo da avaliação do diretor da instituição.

Torna-se, então, importante retomar alguns estudos acerca do processo de feminização do magistério, para explicitar que parece ser esse fenômeno que tornou possível a construção de uma ligação entre grau de tradicionalismo e docência. Como nos lembra Cláudia Vianna (2013, p. 174), o sentido social do magistério como atividade feminina "ultrapassa o fato de sua maioria ser deste sexo". Para a pesquisadora, a utilização do termo feminino, nesse contexto, refere-se "às visões apriorísticas divulgadas na sociedade e não somente ao sexo e/ou às mulheres" (VIANNA, 2013, p. 174). Em sua perspectiva, podemos observar que a feminização do magistério foi um movimento que produziu a feminização do espaço escolar e das atividades docentes, sejam estas exercidas por homens ou por mulheres.

Outros estudos produzidos na década de 1990 convergem para tal conclusão. Fúlvia Rosemberg e Eliana Saparolli (1996, p. 4) descrevem que educadores infantis, independentemente do sexo biológico, "mais se aproximam do que se diferenciam". Para as pesquisadoras, o trabalho exercido pelos educadores infantis não constitui um trabalho feminino pelo maior número de mulheres que exercem essa profissão, "mas porque exerce uma função de gênero feminino vinculada à esfera da vida reprodutiva: cuidar e educar crianças pequenas" (ROSEMBERG; SAPAROLLI, 1996, p. 4). Para Vianna (2013, p. 176), a análise do exercício da docência, a partir de um olhar de gênero, permite observar sua feminização, uma vez que "significados comumente atribuídos às mulheres são acionados por professores e professoras".

O que desejamos mostrar é que, a partir desse processo, que conecta funções e características consideradas naturais do sexo feminino para atividades docentes, torna-se possível criar e aplicar uma escala de tradicionalismo que converge para um resultado positivo, mostrando que quanto maior o grau de tradicionalismo da moça, maior é sua tendência para exercer a docência. Será o 
fortalecimento de variadas teorias, advindas de diferentes campos de saber, como Psicologia e Biologia, para citar apenas dois, sobre uma suposta natureza feminina que vai reforçar a ligação do papel da mulher com o exercício da docência como um destino natural das mulheres que desejassem exercer uma carreira fora do espaço privado da casa e da dedicação exclusiva ao lar. Iremos avançar em nossas análises com relação a tal processo, dando um salto de quase 20 anos para analisar um estudo desenvolvido por outra importante pesquisadora, Guiomar Namo de Mello, que em 1982, ao defender a competência técnica da professora primária, realizou fortes críticas referentes à absolutização do afeto nessa profissão, pois, nas palavras de Mello (1995, p. 117), "quando não sabe-se o que fazer, ama-se”.

\section{ENTRE O COMPROMISSO POLÍTICO E A COMPETÊNCIA TÉCNICA: O MEIO DO CAMINHO}

Nesta seção, como mencionado anteriormente, analisaremos a obra Magistério de $1^{\circ}$ grau: da competência técnica ao compromisso político, escrita por Guiomar Namo de Mello, em 1995. A análise da obra busca recompor um debate que foi importante para o campo da docência, entre as décadas de 1980 e 1990, e continua relevante nos dias atuais, qual seja: a competência técnica e o compromisso político. De acordo com Weber (1996, p. 23), foi o reconhecimento da ligação entre educação escolar e projetos político-sociais que conduziu, nos anos 1980, "à sedimentação de posturas que, percebendo a ação educativa como ato político, a distinguiam ou não da ação política propriamente dita”. É nesse contexto que, de acordo com a autora, vão se situar, por um longo período, perspectivas acadêmicas distintas, entre as quais ela destaca a distinção entre competência técnica e compromisso político realizada por Mello, em 1982, ${ }^{4}$ e a defesa de Arroyo, em $1980,{ }^{5}$ e Gadotti, em $1983,{ }^{6}$ pelo compromisso político como peça fundamental para o exercício docente.

O debate entre competência técnica e compromisso político foi uma das marcas importantes da literatura pedagógica acadêmica dos anos 1980, que parece ter se situado de forma contundente no grupo de orientandos do professor Demerval Saviani. Enquanto Mello defendeu, em sua tese, a necessidade da competência técnica para o compromisso político, seu colega de doutorado, Nosella (1983), defendeu em artigo, após a publicação de seu livro, o compromisso político como horizonte para a construção de uma nova competência técnica, buscando evidenciar a necessidade "de se substituir o velho arsenal de competências técnicas que implicava num compromisso político reacionário ou conservador, com um novo conjunto de técnicas ou, então, com uma metodologia radicalmente nova" (NOSELLA, 1983, p. 93). Procurando recompor tal debate e indicar pontos

5 ARROYO, Miguel. Operários e educadores se identificam, que rumos tomará a educação brasileira? Educação e Sociedade, São Paulo, n. 5, p. 5-23, 1980.

6 GADOTTI, Moacir. Concepção dialética da educação: um estudo introdutório. 2. ed. São Paulo: Cortez; Autores Associados, 1983 
de convergência e divergência nos argumentos dos seus orientandos, Saviani (2011, p. 29) afirma:

Parece-me pois que fundamentalmente não existe oposição entre Guiomar e seus críticos. Existe, sim, uma diferença. Com efeito, o horizonte político de Guiomar, seu compromisso político é o mesmo do Paolo, e de tantos outros entre os quais me incluo. A diferença consiste em que, com os olhos fixos nesse horizonte, Guiomar está empenhada na caminhada para torná-lo menos distante. Está preocupada em encontrar as formas de traduzir praticamente a opção política que tem em comum com seus críticos.

Assim, na leitura de Saviani (2011), Mello (1995), em seu livro, busca encontrar formas para a escola cumprir a função política que lhe é própria e propõe uma tese ousada, na qual a função política da educação escolar se cumpre pela mediação da competência técnica. Outra questão importante relativa às críticas da obra de Mello (1995) refere-se à compreensão de uma defesa pela competência técnica, denominada por Saviani (2011) como “pomo da discórdia”, tal qual uma espécie de neotecnicismo ou até uma volta à pedagogia tecnicista. Como podemos observar na crítica realizada por Nosella (1983, p. 91):

[...] tememos que, apesar das claras afirmações a respeito da necessidade de ainda se criticar e denunciar a prática escolar do sistema que está aí, a tese em pauta possa representar, na prática, uma volta a um novo e disfarçado tecnicismo pedagógico. Ou seja, a tecnologia educacional, dominante nos anos $60-70$ e que vem sendo fortemente questionada pela crítica de cunho marxista, tentaria, obviamente com extrema cautela, retornar ao palco do debate e da prática pedagógica através da tese, bastante confusa que afirma poder-se chegar ao engajamento político, a partir da competência técnica.

Porém, Saviani (2011) aponta que a leitura de Mello (1995), tanto da competência profissional como da competência técnica, ao colocar exigências que implicam uma compreensão mais ampla da escola e da sociedade, ultrapassa, claramente, os limites da pedagogia tecnicista.

Diante do exposto acima, observa-se que o debate da década de 1980, no que concerne à literatura pedagógica, como aponta Saviani (1983, p. 73) na obra Escola e democracia, girava em torno do slogan "a educação é sempre um ato político". Tal afirmativa, de acordo com o pesquisador, "tinha por objetivo combater a ideia anteriormente dominante segundo a qual a educação era entendida como um fenômeno estritamente técnico-pedagógico, portanto, inteiramente autônomo e independente da questão política” (SAVIANI, 1983, p. 73). Nessa perspectiva, o slogan teria sido efetivo; porém, na análise proposta por Saviani da "teoria da 
curvatura da vara", 7 ela teria se curvado muito em direção ao polo político, o que poderia incorrer no "risco de se identificar educação com política, [e] a prática pedagógica com a prática política, dissolvendo-se, em consequência, a especificidade do fenômeno educativo" (SAVINI, 1983, p. 73).

É nesse cenário efervescente, no que concerne à literatura pedagógica brasileira, que se destaca a obra de Guiomar Namo de Mello, pela discussão sobre docência estabelecida pela autora, que oferece elementos importantes para compreendermos o debate desse período. O livro Magistério de $1^{\circ}$ grau: da competência técnica ao compromisso político é dividido em seis capítulos e tem como um dos objetivos descrever o que as professoras, participantes da pesquisa, relatam sobre sua prática e como a representam. Para analisar as representações das professoras, Mello (1995) utilizou dados obtidos por meio de entrevistas, escalas e questionários, para uma amostra de 564 professoras de $1^{\circ}$ grau. As principais representações extraídas do diálogo proposto pela autora, entre a teoria e a empiria, seriam a face boazinha do magistério, a face perversa e a terceira face da prática docente que a pesquisadora chama de bom senso, como podemos ver no excerto a seguir:

Por esse caminho creio ter conseguido distinguir três faces da prática docente. Uma delas é a que chamo de face boazinha. Aí ela me aparece identificada quase que exclusivamente com a relação afetiva, cujo conteúdo é o amor e o carinho que o professor devota aos alunos. A outra face é a que chamo de perversa. Neste caso seu aparecer é o de acusadora da vítima, que em última instância torna-se o réu porque não se adapta à escola. Mas há uma terceira face a que chamo de bom senso. Esta me revela que a aprendizagem e o desenvolvimento do aluno é de fato importante para o professor. E mais, que ele tem certo grau de discernimento da precariedade do atendimento que a escola dá às crianças pobres. (MELLO, 1995, p. 143, grifos da autora)

Essa tipologia estabelecida pelo exercício empírico desenvolvido por Mello (1995) é importante e nos ajuda a compreender as configurações de docência que estavam em disputa naquele período. Começamos explorando a noção de face boazinha do magistério. Para descrever essa primeira face do magistério, a pesquisadora, inicialmente, precisou situar a democratização do ensino historicamente. Para Mello (1995, p. 46), é importante compreender que o crescimento da oferta de escolarização "insere-se no contexto de uma sociedade que cresceu economicamente e vem passando por um processo acelerado de urbanização e modernização com todas as contradições aí decorrentes”. Outro aspecto importante, para recompor o debate pedagógico em disputa no período, consiste em situar que “o ideário

7 Metáfora desenvolvida por Vladimir llyich Ulyanov, conhecido como Lênin, político teórico russo, utilizada em uma palestra na Conferência Brasileira de Educação de 1980, onde, segundo Saviani (2011), a maioria do público era simpatizante do movimento escolanovista. Sendo assim, sua proposta foi forçar a argumentação para o outro lado e defender a escola tradicional, sem que com isso parecesse que a escola tradicional estaria correta, era apenas a utilização da técnica da curvatura da vara: "para endireitá-la não basta colocá-la na posição correta, é preciso curvá-la do lado oposto" (SAVIANI, 2011, p. 64). 
pedagógico brasileiro tem sua matriz no pensamento liberal. A escola é apresentada como promotora de igualdade social na medida em que garante a todos as mesmas oportunidades de ascensão individual” (MELLO, 1995, p. 44).

Uma das principais preocupações dos educadores e das instâncias responsáveis pela política educacional seria, no contexto da democratização do ensino, a extensão quantitativa da escola básica articulada a um projeto de construção de uma sociedade mais igualitária. Surgiriam então, entre os educadores da década de 1920, um “entusiasmo pela educação” e um “otimismo pedagógico” (MELLO, 1995, p. 49). O movimento "escolanovista” seria a expressão brasileira desse movimento e, nesse contexto, a tônica no indivíduo se fortaleceria com a incorporação cada vez mais sofisticada das descobertas da pedagogia, que produziriam um "reducionismo da educação ao psicológico” (MELLO, 1995, p. 50). Tal reducionismo é descrito pela autora a partir da constatação de que os métodos de ensino passariam a ter mais importância do que os conteúdos e o processo mais importância do que o resultado.

Para Mello (1995), o barateamento da educação básica pelo esvaziamento da função docente concretizava-se também por diferentes medidas internas ao ambiente escolar. O primeiro destaque da autora referente a estas medidas relacionava-se à "generalização e à formalização de processos destinados a racionalizar e supervisionar o trabalho docente” (MELLO, 1995, p. 53). Tais processos, em função de um contexto político autoritário, teriam expropriado métodos e etapas do trabalho docente, sem a participação do professor.

O aumento quantitativo da escola pública e gratuita exigiu uma redefinição do modelo anterior de ensino em que "o professor, à semelhança do artesão, atendia as demandas de uma clientela mais homogênea porque pré-selecionada" (MELLO, 1995, p. 54). Mas, como aponta a autora, tal redefinição não precisaria ter ocorrido na separação entre concepção e execução e em uma rígida estrutura de etapas e funções ao melhor modelo fabril. Como procuroul-se mostrar na seção anterior, o declínio de uma concepção artesanal da docência no Brasil ocorreu a partir de uma burocratização das atividades docentes. Na próxima seção, volta-se com mais atenção para as críticas relacionadas ao parcelamento do trabalho docente a partir desta mudança de concepção do trabalho.

Após ter explorado algumas das questões sobre a face boazinha do magistério, passa-se, agora, para as análises da face perversa. De acordo com Mello (1995, p. 144), na obra em questão, o lado perverso do magistério "assume o conteúdo do pensamento liberal e as contradições internas desse pensamento". Aqui vale a pena atentar para as reflexões realizadas pela pesquisadora acerca das causas que justificariam o fracasso escolar da criança carente por meio das crenças dos professores. Um grupo bastante significativo de professoras participantes do estudo assumiu uma estratégia que Mello (1995, p. 93) denominou "culpar a vítima”. Nessa estratégia, duas seriam as condições da própria criança que as professoras apontariam como os principais motivos do seu fracasso como aluna na trajetória escolar: falta de esforço e burrice.

Outra questão que aparece nesta face do magistério para justificar o fracasso de alunos das classes populares estaria relacionada com seu ambiente familiar, 
tendo centralidade o desinteresse e o abandono dos pais. Ainda, de acordo com Mello (1995, p. 94), ficou evidente, nas análises estatísticas, que “a culpa da vítima e responsabilidade da pobreza e do desinteresse da família foram mais altas que a do conjunto responsabilidade da escola”. Esta constatação leva Mello (1995, p. 117) a retomar a face boazinha do magistério para então afirmar: "Quando não se sabe o que fazer, ama-se”. Conforme sua argumentação, “este seria o princípio norteador do senso comum e da prática do magistério, ainda que o bom senso nele seja incluído". A autora desenvolve a hipótese que relaciona o esvaziamento do conteúdo técnico pedagógico e a absolutização do afeto nas atividades docentes:

Será, portanto retirando de sua atividade o conteúdo técnico-profissional, e o seu sentido de trabalho assalariado, e absolutizando seu caráter afetivo, que o professor vai realizar as acomodações necessárias entre sua vivência cotidiana e seus valores mais gerais. Não estou negando a dimensão afetiva do magistério. Como toda atividade que envolve relacionamento humano ela incluirá sempre essa dimensão. Entretanto, quando ela é absolutizada, é muito provável que isso seja uma maneira de contornar, pelo caminho do sentimento, problemas que reclamam a competência do especialista. Não do especialista entendido num sentido estritamente tecnicista, pois neste caso as máquinas de ensinar poderiam ser mais eficientes. Mas de profissionais que saibam usar a cabeça e as mãos para enfrentar os desafios que lhes chegam também e, sobretudo, pela via da interação afetiva e sentimental com o aluno. (MELLO, 1995, p. 53)

Como pode-se observar, Mello (1995) não nega o caráter afetivo da atividade docente, apontado esse caráter como inerente de uma atividade que envolve relacionamento humano. A denúncia que a pesquisadora realiza em sua obra consiste em uma absolutização do caráter afetivo em detrimento do conteúdo técnico profissional da professora. Afeto, amor e carinho seriam as respostas da professora, especialmente, para o aluno carente que frequentemente fracassa na escola. É esse diagnóstico que permite Mello $(1995,77)$ afirmar que a "vítima se transforma em réu, ainda que muito amada”, mostrando que a face boazinha do magistério pode borrar-se com a perversa.

Todavia a obra não apresenta um diagnóstico pessimista ou catastrófico do trabalho docente, pois, como apontamos na abertura desta seção, Mello (1995) acredita na competência profissional e na competência técnica como elementos que podem ser desenvolvidos nas professoras e garantir que a escola cumpra seu compromisso político com uma educação que se constitua realmente para todos. Para tanto, a pesquisadora se apoia na face do magistério que denominou como "bom senso", tal como podemos observar a seguir. 
prática dentro dela respondem em alguma medida pelo fracasso das crianças pobres; e se, por outro lado, ele combina isso com a face perversa e a face boazinha pelas quais expressa o aparecer dessa prática, fui levada a supor que faltava um personagem nesse cenário. Esse personagem, segundo a síntese que faço, é o saber fazer aquilo que o bom senso aponta como necessário. A isso chamo de competência técnica, que poderia ser objetivada em termos do domínio do conteúdo do saber escolar e dos métodos adequados para transmitir esse conteúdo do saber escolar a crianças que não apresentam as precondições idealmente estabelecidas para sua aprendizagem. (MELLO, 1995, p. 145)

Seria a partir do bom senso que, acreditava Mello (1995), se desenvolveria a competência técnica dos professores, tão importante para o desenvolvimento do seu compromisso político. Para que isto ocorresse, de acordo com a pesquisadora, seria necessário que o professor passasse de especialista para dirigente. De acordo com Fontana (2010), o papel social do professor sustentado pela tese de Mello (1995) seria o de dirigente que articularia os saberes técnicos relativos à atividade docente com o seu fazer político. Para Betty Oliveira e Newton Duarte (1990, p. 38, grifo dos autores), em reflexão realizada, posteriormente, sobre a concepção da prática pedagógica do educador dirigente, não bastaria que a ação pedagógica fosse compreendida como eminentemente política em si, seria necessário que ela fosse "intencionalmente questionada e o mais profundamente compreendida possível, para que, ao ser elaborada e realizada, se torne uma ação política também para si”. Entendemos que o debate entre a competência técnica e o compromisso político do professor continua sendo uma pauta importante para o campo dos estudos em docência; o que desejamos mostrar na próxima seção é que o debate acadêmico brasileiro no final dos anos 1980 e início dos 1990 apresenta um deslocamento para pensar a prática do professor, voltando suas análises para o que acontecia no interior da sala de aula.

\section{O PROFESSOR E SUA PRÁTICA: ABRINDO NOVOS CAMINHOS PARA A PESQUISA EM EDUCAÇÃO}

As discussões sobre a prática docente, ao longo das décadas analisadas, tiveram diferentes focos e ancoraram-se em distintas perspectivas teóricas. As análises desta seção têm como foco a obra 0 bom professor e a sua prática (CUNHA, 1994), que teve como principal objetivo descrever a prática do bom professor, olhando para as suas atividades cotidianas e observando o dia a dia na sala de aula.

O livro é dividido em cinco partes: a primeira justifica as origens e motivações do trabalho, entrelaçando com a trajetória acadêmica e profissional da pesquisadora; a segunda discute qual seria a concepção de bom professor do ponto de vista dos alunos; na terceira, o foco volta-se para o professor e como ele percebe sua trajetória; na quarta, a pesquisadora analisa e discute as práticas do bom professor, a partir de observações realizadas nas salas de aula; e, na quinta e 
última parte, são realizadas uma análise crítica do modelo de ensino encontrado e uma problematização acerca da formação dos educadores.

Iniciamos apresentando as análises da pesquisadora sobre as concepções acerca do que seria o bom professor, do ponto de vista dos alunos. O primeiro aspecto destacado por Cunha (1994, p. 70) refere-se ao compromisso dos professores: "É inegável, porém, que a forma de ser e de agir do professor revela um compromisso. E é esta forma de ser que demonstra mais uma vez a não-neutralidade do ato pedagógico”. O segundo aspecto diz respeito à metodologia do professor. "Um professor que acredita nas potencialidades do aluno, que está preocupado com sua aprendizagem e com seu nível de satisfação com a mesma, exerce práticas de sala de aula de acordo com essa posição”. Outro destaque da pesquisadora concerne ao fato de que os melhores professores não seriam aqueles considerados bonzinhos pelo coletivo, ao contrário, “o aluno valoriza o professor que é exigente, que cobra participação e tarefas. Ele percebe que esta é também uma forma de interesse se articulada com a prática cotidiana da sala de aula" (CUNHA, 1994, p. 71).

A autora também ressalta um aspecto não mencionado pelos alunos sobre o bom professor, que diz respeito ao seu posicionamento político. De acordo com Cunha (1994, p. 71), “quando os alunos hoje apontam o bom professor, só em situações raras referem-se ao seu posicionamento político”. Isso não significa inferir que esta não seria uma dimensão aprendida por esses alunos, ou que não consiste em um aspecto importante da docência do bom professor, entretanto, "ao que parece, este não é um dado consciente para os alunos, e talvez sequer seja para o professor" (CUNHA, 1994, p. 72). Em resumo, o bom professor, na opinião dos alunos participantes do estudo, seria "aquele que domina o conteúdo, escolhe formas adequadas de apresentar a matéria e tem bom relacionamento com o grupo" (CUNHA, 1994, p. 72).

Interessa, neste momento, apresentar as análises relativas ao "fazer do professor", que Cunha (1994) divide em três categorias: os procedimentos, as habilidades e o contexto. Com relação aos procedimentos, a pesquisadora destaca, como principal técnica, a exposição oral:

A exposição oral foi a técnica a que mais assisti. O objetivo de seu uso variou como resultante do momento em que ela acontecia, em relação ao desenvolvimento do currículo. Assisti a aulas de introdução de nova unidade, outras de fechamento deste segmento didático; assisti às aulas que precediam a execução de exercícios, outras foram dadas em cima de tarefas realizadas pelos alunos. Em duas ocasiões observei professores em discussão circular com os alunos, como resultante de estudo de casos. Nas aulas de laboratório ou nas aulas práticas em geral, os professores faziam uma preleção inicial, davam instruções e, depois, os alunos trabalhavam. Normalmente foram aulas de maior duração, que previam a intermitência da atividade do aluno com a do professor. Em todos os casos observei a preocupação dos 
De acordo com as observações da autora, a organização pedagógica proposta por aqueles que eram considerados bons professores estava "basicamente organizada em cima da fala do professor", evidenciando uma proposta na qual o docente constituía-se na "principal fonte da informação sistematizada" (CUNHA, 1994, p. 135). Com base nas entrevistas realizadas com os professores, posteriormente às observações, pode-se constatar que tal organização parece advir das experiências escolares vivenciadas pelos docentes que tendiam a reproduzir práticas que consideravam de sucesso em suas aulas. De acordo com Cunha (1994, p. 136), "Há pouca possibilidade de que nossos interlocutores tivessem tido experiências de discussões em classe, com professores que contestassem a ideologia existente, que tentassem construir o conhecimento de forma coletiva”. Com relação à expectativa dos alunos, a pesquisadora também infere que eles, possivelmente, estariam condicionados com relação a que tipo de aula esperavam. Então, seria "provável que professores e alunos assim se comportem por falta de vivência em outro tipo de abordagem metodológica” (CUNHA, 1994, p. 136).

As habilidades de ensino dos bons professores foram organizadas em cinco categorias pela pesquisadora: habilidades relacionadas com a organização do contexto de aula; habilidades de incentivo à participação; habilidades com relação ao trato com a matéria; habilidades de variação de estímulos; e habilidades relacionadas ao uso da linguagem. O conjunto de habilidades descritas pela autora é importante, pois ajuda a compreender quais eram as características daquele período histórico que consistiam como importantes para que um docente fosse considerado um bom professor. Cunha (1994, p. 148) ainda destaca que "uma das conclusões que me parece fundamental é a de que há um alto índice de coerência entre a descrição que os docentes fizeram de sua prática pedagógica e o que realmente acontece na sala de aula”. Porém, ao final, a autora faz um pequeno alerta e afirma que se pode "fazer uma crítica a algumas representações um pouco ingênuas do processo ensino-aprendizagem” (CUNHA, 1994, p. 148).

Com relação às análises da pesquisadora referentes à prática do bom professor, importa destacar outro elemento importante relacionado ao contexto maior em que tais práticas encontram-se inseridas, como podemos observar no excerto a seguir:

Outra inferência que pude fazer é que não se pode reduzir $o$ ato de ensino do professor somente aos aspectos observáveis na sala de aula. Isto porque, a par dessas atividades, existem outras que têm lugar também importante no processo ensino-aprendizagem: conversas com os alunos fora da sala de aula, preparo das aulas, forma de convivência com os colegas etc.

[...] A observação da sala de aula é imprescindível para a análise do processo escolar, mas é importante percebê-la situada no contexto das atitudes e atividades outras do professor. 0 
que vale aprender são as situações escolares no seu conjunto, na sua relação com um conjunto sociológico, localizado no tempo e no espaço. (CUNHA, 1994, p. 149)

Com esse destaque da pesquisadora, queremos chamar atenção para um deslocamento da pesquisa acadêmica com relação à docência, passando de uma centralidade nas discussões acerca do trabalho realizado na sala de aula para um olhar mais abrangente e complexo sobre as atividades docentes (TARDIF; LESSARD, 2014). Mesmo que o estudo analisado tenha como centralidade as atividades realizadas na sala de aula, a pesquisadora extrapola suas análises para o contexto da instituição, apontando como importantes as relações estabelecidas pelo professor nesses espaços para que ele seja considerado um bom professor. Tal mudança é significativa e parece seguir representativa no que se refere à docência contemporânea.

A autora, ao encaminhar-se para as conclusões do seu estudo, realiza algumas ressalvas quanto às habilidades e práticas dos bons professores que ela encontrou a partir de sua investigação empírica. Tais apontamentos referem-se, especialmente, às concepções que naquele período eram construídas acerca do que seria o bom professor. Ela, então, afirma que "os bons professores têm muitas condições pedagógicas e didáticas tidas como significativas nas nossas instituições escolares de hoje” (CUNHA, 1994, p. 167). Todavia, esta compreensão estaria assentada em uma compreensão de ensino que "tem no docente o centro do processo de ensinar e aprender" (CUNHA, 1994, p. 167), sendo que os professores teriam como principal função "transferir seu próprio conhecimento aos alunos" (CUNHA, 1994, p. 167). Nesse contexto, a pesquisadora aponta algumas limitações acerca desta representação que apresentamos no excerto a seguir:

Como exemplo, cito que BONS PROFESSORES desenvolvem um grande número de habilidades de ensino, tais como: fazer perguntas, variar estímulos, relacionar o conteúdo com outras áreas etc. Todavia, não temos ainda BONS PROFESSORES que estejam mais voltados a desenvolver habilidades nos alunos. O professor é capaz de apresentar o melhor esquema do conteúdo a ser desenvolvido em aula, mas não conhece procedimentos sobre como fazer o aluno chegar ao mapeamento próprio da aprendizagem que está realizando. O BOM PROFESSOR relata e referencia resultados de suas pesquisas, mas pouco estimula o aluno a fazer as suas próprias, mesmo que de forma simples. [...] Nessa perspectiva percebo que, mesmo os BONS PROFESSORES, repetem uma pedagogia passiva, muito pouco crítica e criativa. (CUNHA, 1994, p. 167-168, grifos da autora)

O que desejamos destacar com relação às nossas análises da obra de Cunha refere-se ao surgimento do que Candau (1995) nomeou, alguns anos após, como uma "nova didática". Para a pesquisadora, no contexto dos anos 1990, era 
necessário superar uma "busca incessante do método único capaz de ensinar tudo a todos. Consequentemente é importante superar certa visão reducionista do método didático" (CANDAU, 1995, p. 30). Assim, o desafio para o campo da didática seria assumir que tal método era composto por diferentes estruturantes e não tornar exclusivo qualquer um deles. Para Candau (1995, p. 30), “o desafio está na superação do reducionismo e na ênfase na articulação”. Ao analisarmos o estudo desenvolvido por Cunha no início dos anos 1990 e suas análises sobre a prática dos professores, atentamos para uma mudança na forma de pesquisar a docência centrada no fazer docente e nas relações didáticas e pedagógicas desse fazer. Também destacamos as críticas realizadas pela pesquisadora, a forma de organizar a prática pedagógica centrada no professor e na transmissão dos conteúdos e a defesa de uma nova forma de organizar as atividades docentes mais crítica e criativa. Compreendemos que tais destaques realizados pela pesquisadora abrem caminhos para novas pesquisas em educação, que passam a defender uma nova forma de organizar os processos pedagógicos com ênfase não mais no professor e nos processos de ensino, mas sim nos alunos e nos processos de aprendizagem.

\section{CONSIDERAÇÕES FINAIS}

Nesse artigo assumimos a docência brasileira como objeto de investigação a partir de um olhar para seu processo de constituição histórica. Todavia, a perspectiva histórica adotada nesse trabalho buscou distanciar-se de uma posição que procura glorificar, reeditar e julgar o passado. Como explica Villela (2005, p. 78), o olhar histórico sobre os documentos objetiva "compreender o sentido do movimento que define as mudanças e permanências dos processos sociais”. Assim, ao analisarmos três importantes obras acadêmicas brasileiras escritas na segunda metade do século XX, não objetivamos construir explicações, nem estabelecer ligações explicativas com o presente. Olhamos para o passado como "um território de diálogo com as novas gerações e [buscamos] algumas possibilidades de intuições criativas para os impasses que se colocam no presente desafiador" (VILLELA, 2005, p. 78).

Acreditamos que, para consolidarmos uma pauta investigativa sobre a docência brasileira, precisamos investir em estudos históricos que, ao atentarem para a literatura pedagógica, nos auxiliem a problematizar como tais movimentos constituíram-se no interior dessa trama discursiva. Assim, esse estudo buscou oferecer uma contribuição para o campo da formação de professores e da didática, ao mapear três tendências analíticas sobre tais temáticas no interior do pensamento pedagógico brasileiro da segunda metade do século XX (SCHERER, 2019).

Como buscamos mostrar nesse estudo, se, nos anos 1960, foi importante pesquisar quem eram as moças que ingressavam no magistério, quais eram suas motivações e quais as fragilidades apresentadas pelos cursos normais diante das primeiras tentativas de democratização do acesso à educação, os anos 1980, com a democratização da educação em curso, foi relevante debater quem eram as professoras e quais os desafios para a tarefa docente em face dessa ampliação de público nas escolas. Assim, o debate entre a competência técnica e o compromisso político dos educadores pautou a discussão acadêmica desse período. Na década 
de 1990, por fim, as investigações sobre a docência voltaram-se para a prática dos professores e defenderam a constituição de uma nova didática não mais centrada no professor como fonte do conhecimento, mas que passava a olhar para o aluno e seus processos de aprendizagem. Olhar para a literatura pedagógica nesse estudo permitiu, além de um reencontro com importantes investigações desenvolvidas por pesquisadoras brasileiras, mapear algumas tendências que têm contribuído para a constituição da nossa forma de ser professor e professora. Acreditamos que o delineamento dessas perspectivas históricas favorecerá a ampliação das possibilidades interpretativas para a formação de professores no século XXI.

\section{REFERÊNCIAS}

CANDAU, Vera Maria. Rumo a uma nova didática. Petrópolis: Vozes, 1995.

CASTRO, Edgardo Manuel. Vocabulário de Foucault: um percurso pelos seus temas, conceitos e autores. Belo Horizonte: Autêntica, 2009.

CUNHA, Maria Isabel da. O bom professor e a sua prática. São Paulo: Papirus, 1994.

FISCHER, Rosa Maria Bueno. Trabalhar com Foucault: arqueologia de uma paixão. Belo Horizonte: Autêntica, 2012.

FONTANA, Roseli A. Como nos tornamos professoras? Belo Horizonte: Autêntica, 2010.

GAUTHIER, Clarisse. Por uma teoria da pedagogia: pesquisas contemporâneas sobre o saber docente. Ijuí: Editora da Unijuí, 2006.

GOUVEIA, Aparecida Joly. Professôras de amanhã: um estudo de escolha ocupacional. Centro Brasileiro de Pesquisas Educacionais, Instituto Nacional de Estudos Pedagógicos, Ministério da Educação e Cultura, 1970. (Série VI, Sociedade e Educação, v. 7).

HARGREAVES, Andy. Os professores em tempos de mudança: o trabalho e a cultura dos professores na idade pós-moderna. Lisboa: McGraw, 1998.

LÜDKE, Menga. Aparecida Joly Gouveia. Recife: Massanga, 2010.

MELLO, Guiomar Namo. Magistério de $1^{\circ}$ grau: da competência técnica ao compromisso político. 11. ed. São Paulo: Cortez, 1995.

NOSELLA, Paolo. Compromisso político como horizonte da competência técnica. Educação \& Sociedade, Campinas, v. 5, n. 14, p. 91-97, 1983.

OLIVEIRA, Betty A.; DUARTE, Newton. Socialização do saber escolar. São Paulo: Cortez, 1990.

PAOLI, Niuvenius Junqueira. As relações entre ciências sociais e educação nos anos 50/60 a partir das histórias e produções intelectuais de quatro personagens: Josildeth Gomes Consorte, Aparecida Joly Gouveia, Juarez Brandão Lopes e Oracy Nogueira. Tese (Doutorado em Educação) - Universidade de São Paulo, São Paulo, 1995.

PIMENTA, Selma Garrido. Formação de professores: saberes da docência e identidade do professor. Revista da Faculdade de Educação, São Paulo, v. 22, n. 2, p. 72-89, jan. 1996.

ROSEMBERG, Fúlvia; SAPAROLLI, Eliana. O homem como educador infantil. In: REUNIÃO DA ANPOCS, 20. Caxambu/MG, out. 1996. Anais [...]. Rio de Janeiro: Anpocs, 1996.

SANTOMÉ, Jurjo Torres. Profesoras y profesores en el ojo del huracán. Foro de Educación, n. 7-8, p. 81-102, maio 2006. 
SAVIANI, Demerval. Pedagogia histórico-crítica: primeiras aproximações. 11. ed. Campinas: Autores Associados, 2011.

SCHERER, Renata Porcher. A desfeminização do magistério: uma análise da literatura pedagógica da segunda metade do século XX. Tese (Doutorado em Educação) - Universidade do Vale do Rio dos Sinos, São Leopoldo, 2019.

TARDIF, Maurice. Saberes docentes e formação profissional. Petrópolis: Vozes, 2010.

TARDIF, Maurice; LESSARD, Claude. As transformações atuais do ensino: três cenários possíveis na evolução da profissão de professor? In: TARDIF, Maurice; LESSARD, Claude. 0 ofício de professor: história, perspectivas e desafios internacionais. Petrópolis: Vozes, 2014.

VEIGA-NETO, Alfredo. Grupo de Estudos e Pesquisas em Currículo e Pós-Modernidade/ GEPCPós: concepções sobre a prática. In: REUNIÃO ANUAL DA ASSOCIAÇÃO NACIONAL DE PÓS-GRADUAÇÃO E PESQUISA EM EDUCAÇÃO (ANPED), 31., Caxambu, 2008. Anais [...] Rio de Janeiro: ANPEd, 2008.

VIANNA, Cláudia Pereira. A feminização do magistério na educação básica e os desafios para a prática e a identidade coletiva docente. In: YANNOULAS, Silvia Cristina (coord.). Trabalhadoras: análise da feminização das profissões e ocupações. Brasília: Abaré, 2013. p. 159-180.

VILLELA, Heloísa de Oliveira. O mestre-escola e a professora. In: LOPES, Eliana Marta Teixeira; FARIA FILHO, Luciano Mendes; VEIGA, Cynthia Greive (org.). 500 anos de educação no Brasil. Belo Horizonte: Autêntica, 2000. p. 95-133.

VILLELA, Heloisa de O. S. Entre o “saber fazer" e a profissionalização: a escola normal do século XIX e a constituição da cultura profissional docente. In: MIGUEL, Maria E. B.; CORRÊA, Rosa L. T. (org.). A educação escolar em perspectiva histórica. São Paulo: Autores Associados, 2005. p. 77-101.

WEBER, Silke. o professorado e o papel da educação na sociedade. Campinas: Papirus, 1996.

\section{COMO CITAR ESTE ARTIGO}

SCHERER, Renata Porcher. Modos de constituição da docência brasileira: tradicionalismo, competência técnica e boas práticas. Cadernos de Pesquisa, São Paulo, v. 50, n. 175, p. 274-293, jan./mar. 2020. https://doi.org/10.1590/198053146535 